\section{Percutaneous radiofrequency ablation for hepatic metastasis of colorectal cancer: assessment of tumor visibility and the feasibility of the procedure with planning ultrasonography}

Jeong Woo Bae', Min Woo Lee ${ }^{2,3}$, Tae Wook Kang ${ }^{2,3}$, Kyoung Doo Song ${ }^{2,3}$, Dong Ik Cha ${ }^{2}$, Ji Hye $\mathrm{Min}^{2}$, Hyunchul Rhim ${ }^{2,3}$

\begin{abstract}
${ }^{1}$ Sungkyunkwan University School of Medicine, Seoul; ${ }^{2}$ Department of Radiology and Center for Imaging Science, Samsung Medical Center, Sungkyunkwan University School of Medicine, Seoul; ${ }^{3}$ Department of Health Sciences and Technology, SAIHST, Sungkyunkwan University, Seoul, Korea
\end{abstract}

Purpose: The aim of this study was to assess the incidence and causes of percutaneous radiofrequency ablation (RFA) infeasibility in cases of metastatic colorectal cancer and to evaluate factors affecting the invisibility of the tumor on planning ultrasonography (US).

Methods: This study screened 386 patients who underwent planning US using fusion imaging and/or contrast-enhanced US for percutaneous RFA for suspected metastatic colorectal cancer between January 2013 and December 2020, from whom 136 patients with a single hepatic metastasis from colorectal cancer measuring $<3 \mathrm{~cm}$ were included. The factors related to the infeasibility of percutaneous RFA were investigated. Univariate and multivariate analyses were performed to assess the factors associated with tumor invisibility on planning US.

Results: Among the 136 patients, percutaneous RFA was considered infeasible in 24.3\% (33/136) due to a high risk of the heat-sink effect caused by the abutment of a large vessel $(n=12)$, an inconspicuous tumor on planning US $(n=11)$, a high risk of collateral thermal damage to an adjacent organ $(n=8)$, and the absence of a safe electrode path $(n=2)$. In univariate and multivariate analyses, tumor size was a statistically significant factor affecting invisibility on planning US ( $\mathrm{P}=0.003$ and $\mathrm{P}=0.018$, respectively).

Conclusion: Percutaneous RFA was infeasible in approximately one-fourth of patients with metastatic colorectal cancer. The reason for the infeasibility was mainly an unfavorable tumor location and invisibility on planning US. Small tumor size was the sole significant factor affecting the invisibility of hepatic metastases on planning US.

Keywords: Radiofrequency ablation; Metastasis; Liver; Planning ultrasonography; Detection Key points: Ultrasound-guided percutaneous radiofrequency ablation is infeasible in approximately one-fourth of patients with colorectal liver metastasis smaller than $3 \mathrm{~cm}$ in diameter. Main reason for infeasibility of percutaneous radiofrequency ablation is unfavorable tumor location for thermal ablation and invisibility of tumor on planning ultrasound. Small size of colorectal liver metastasis is a sole significant factor associated with invisibility of tumor on planning ultrasound.

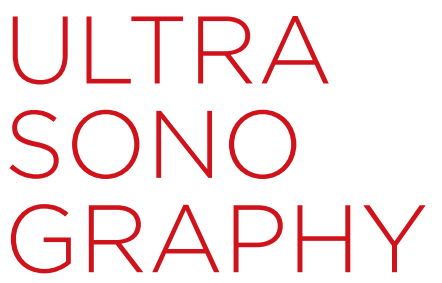

ORIGINAL ARTICLE

https://doi.org/10.14366/usg.21050 pISSN: 2288-5919 • elSSN: 2288-5943 Ultrasonography 2022;41:189-197

Received: March 4, 2021

Revised: June 9, 2021

Accepted: June 22, 2021

Correspondence to:

Min Woo Lee, MD, PhD, Department of Radiology and Center for Imaging Science, Samsung Medical Center, Sungkyunkwan University School of Medicine, 81 Irwon-ro, Gangnam-gu, Seoul 06351, Korea

Tel. +82-2-3410-2518

Fax. +82-2-3410-2559

E-mail: leeminwoo0@gmail.com

This is an Open Access article distributed under the terms of the Creative Commons Attribution NonCommercial License (http://creativecommons.org/ licenses/by-nc/4.0/) which permits unrestricted noncommercial use, distribution, and reproduction in any medium, provided the original work is properly cited.

Copyright (C) 2022 Korean Society of Ultrasound in Medicine (KSUM)

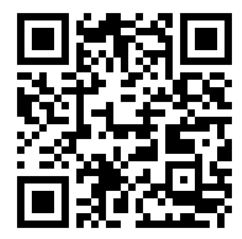

How to cite this article:

Bae JW, Lee MW, Kang TW, Song KD, Cha DI, $\mathrm{Min} \mathrm{JH}$, et al. Percutaneous radiofrequency ablation for hepatic metastasis of colorectal cancer: assessment of tumor visibility and the feasibility of the procedure with planning ultrasonography. Ultrasonography. 2022 Jan;41(1):189-197. 


\section{Introduction}

The liver is the most prevalent metastasis site of colorectal cancer, with at least $25 \%$ of colorectal cancer patients experiencing metastasis to the liver during their lifetime [1]. Surgical resection is the standard treatment for hepatic metastasis as it provides better local tumor control, disease-free survival, and overall survival than radiofrequency ablation (RFA) for metastatic colorectal cancer [2]. However, due to patients' predisposing conditions at the time of diagnosis, only $10 \%-20 \%$ of patients can be treated surgically [3]. Percutaneous RFA has been used as an alternative to surgical resection in these situations $[4,5]$. Before conducting RFA for liver tumors, planning ultrasonography (US) is performed to determine the feasibility of percutaneous US-guided RFA [6-8]. With recent advances in US technology, including fusion imaging of real-time US and computed tomography (CT) or magnetic resonance imaging (MRI), as well as contrast-enhanced US (CEUS), it has become possible to effectively ablate small tumors, which was infeasible in the past [9-12].

Earlier studies investigated factors associated with the infeasibility of percutaneous RFA and the invisibility of the tumor on planning US $[6-8,13]$. However, B-mode US was used in almost all studies on hepatocellular carcinoma (HCC), and advanced US technology, such as fusion imaging, has rarely been used [10]. Previous studies reported that the infeasibility of RFA was mainly due to inconspicuous tumors on B-mode US. The invisibility of the tumors resulted from their small size, subphrenic location, the presence of liver cirrhosis, and macronodular cirrhosis $[7,8]$. Given that hepatic metastases are not related to chronic hepatitis or liver cirrhosis, most patients with hepatic metastases would be expected to have a normal liver. For these reasons, the results of planning US to determine the technical feasibility of percutaneous RFA for hepatic metastasis would differ from those in patients with HCC.

Therefore, this study investigated the causes of infeasibility of percutaneous RFA for metastatic colorectal cancer and evaluated factors affecting the invisibility of tumors on planning US using fusion imaging and CEUS.

\section{Materials and Methods}

\section{Compliance with Ethical Standards}

The institutional review board (IRB) of the Samsung Medical Center approved this retrospective study (IRB \# 2020-08-084), and the requirement for informed consent was waived.

\section{Patients}

From January 2013 to December 2020, 386 planning US procedures were performed for patients with suspected hepatic metastasis detected on liver CT or MRI, to determine the feasibility of percutaneous RFA. Among them, 250 patients were excluded for the following reasons: multiple tumors $(n=230)$, metastasis from other cancers ( $n=10)$, possible atypical HCC in a cirrhotic liver $(n=1)$, benign disease on percutaneous biopsy, or follow-up CT or MRI $(n=6)$, or a tumor size $>3 \mathrm{~cm}(n=3)$. Eventually, 136 patients were included with a single hepatic metastasis from colorectal cancer measuring $<3 \mathrm{~cm}$. Hepatic metastases were diagnosed based on pathologic proof by percutaneous biopsy $(n=2)$, subsequent hepatic resection ( $n=16)$, or typical imaging findings on liver CT or MRI $(n=118)$. A flow diagram of patient selection is shown in Fig. 1.

\section{Planning US}

The mean time interval between CT/MRI and planning US was $11.0 \pm 9.8$ days. All planning US procedures were performed using US machines (LOGIQ E9 or LOGIQ E10; GE Healthcare, Waukesha, WI, USA) by one of five radiologists (H.K.L., H.R., M.W.L., K.D.S., and T.W.K.) who had experience of more than 100 cases of percutaneous RFA of liver tumors. Before planning US, the radiologists carefully reviewed the CT or MRI scans, and the patients were positioned appropriately for a US examination based on the tumor location. In general, if the tumor was located in the liver dome and the
386 Patients who underwent planning US for liver metastasis from colorectal cancer (Jan 2013-Oct 2020)
250 Patients were sequentially excluded

- 230 Multiple tumors

- 10 Metastasis from other cancers

- 1 Possible atypical HCC in a cirrhotic liver

- 6 Benign disease on biopsy or image

- 3 Tumor size $>3 \mathrm{~cm}$
Fig. 1. Flow diagram of patient selection for the study. US, ultrasonography; HCC, hepatocellular carcinoma. 
sonographic window was considered to be affected by the lung or rib shadow, the semi-erect position using a tilting table was preferred because the sonographic window is enhanced for hepatic dome lesions in this position [14]. Planning US was performed using fusion imaging (Volume Navigation, LOGIQ E9, or LOGIQ E10) of real-time US and pre-acquired CT/MRI scans [10]. The radiologists searched for metastatic nodules on B-mode US, based on fused CT/MRI scans. The radiologists evaluated and assessed lesion conspicuity and the feasibility of percutaneous RFA. If the lesion was not sufficiently conspicuous, CEUS with gaseous perflubutane (Sonazoid, GE Healthcare, Oslo, Norway) was added to the fusion imaging at the time of planning US [15]. The necessity of CEUS was determined by the attending radiologists who performed the planning US.

\section{Outcome Assessment}

When percutaneous RFA was infeasible, the cause of the infeasibility of percutaneous RFA was categorized based on radiologic reports and the stored images of planning US on a picture archiving and communication system (PACS) (Centricity, GE Healthcare, Milwaukee, WI, USA) as follows: (1) an inconspicuous tumor on planning US; (2) a high risk of the heat-sink effect due to the abutment of a large vessel, defined as the portal vein, hepatic vein or inferior vena cava with vessel caliber of $3 \mathrm{~mm}$ or larger [16]; (3) a high risk of collateral thermal damage to an adjacent organ due to close proximity; and (4) the absence of a safe electrode path [6].

If the metastasis could not be identified even after CEUS, the lesion was regarded as an invisible tumor. The size of the tumor was based on the maximal diameter on CT/MRI scans, which was measured using an electronic caliper on the PACS. The distance between the upper margin of the tumor and the diaphragm was measured using coronal or sagittal CT/MRI scans.

\section{Statistical Analysis}

The univariable associations between individual variables for the visibility of the tumor was tested using the two-sample t test or Wilcoxon rank-sum test for continuous variables (the size of the tumor, distance from the diaphragm, creatinine, age, albumin, total bilirubin, prothrombin time, platelet count, carcinoembryonic antigen, and carbohydrate antigen 19-9) and the chi-square test or Fisher exact test for categorical variables (sex, body mass index, segmental location of the tumor, prior history of hepatic resection or chemotherapy, and presence of liver disease) as appropriate. Multiple logistic regression analysis was performed to test the significance of the factors adjusted for the other variables. Variables with a P-value $<0.10$ in the univariate analysis were used for multiple logistic regression analysis. For both the univariate and
Table 1. Baseline characteristics of the 136 patients

\begin{tabular}{|c|c|}
\hline Characteristic & Value \\
\hline Age (year) & $60.3 \pm 11.6$ \\
\hline Distance from the diaphragm $(\mathrm{cm})$ & $1.6(0-7.8)$ \\
\hline Albumine (g/dL) & $4.3(3-5.1)$ \\
\hline Total bilirubin (mg/dL) & $0.5(0.2-2.4)$ \\
\hline PT (INR) & $1.0(0.9-1.5)$ \\
\hline Platelet count $\left(\times 10^{9} / \mathrm{L}\right)$ & $241(84-462)$ \\
\hline Creatinine (mg/dL) & $0.8(0.4-3.0)$ \\
\hline $\mathrm{CEA}(\mathrm{ng} / \mathrm{mL})$ & $3.3(0.5-594.9)$ \\
\hline CA19-9 (U/mL) & $13.8(1.2-583.1)$ \\
\hline \multicolumn{2}{|l|}{ Sex } \\
\hline Female & $49(36.0)$ \\
\hline Male & $87(64.0)$ \\
\hline \multicolumn{2}{|l|}{ BMI $\left(\mathrm{kg} / \mathrm{m}^{2}\right)$} \\
\hline$<25$ & $87(64.0)$ \\
\hline$\geq 25$ & $49(36.0)$ \\
\hline \multicolumn{2}{|l|}{ Segment } \\
\hline । & $7(5.2)$ \\
\hline$\|$ & $7(5.2)$ \\
\hline III & $11(8.1)$ \\
\hline IV & $21(15.4)$ \\
\hline V & $9(6.6)$ \\
\hline VI & $27(19.9)$ \\
\hline$V \|$ & $17(12.5)$ \\
\hline VIII & $37(27.2)$ \\
\hline \multicolumn{2}{|l|}{ Tumor size $(\mathrm{cm})$} \\
\hline$\leq 1$ & $45(33.1)$ \\
\hline $1.1-2.0$ & $80(58.8)$ \\
\hline $2.1-3.0$ & $11(8.1)$ \\
\hline \multicolumn{2}{|l|}{ Chemotherapy } \\
\hline No & $66(48.5)$ \\
\hline Yes & $70(51.5)$ \\
\hline \multicolumn{2}{|l|}{ Previous hepatic resection } \\
\hline No & $120(88.2)$ \\
\hline Yes & $16(11.8)$ \\
\hline \multicolumn{2}{|l|}{ Liver disease } \\
\hline No & $133(97.8)$ \\
\hline Chronic hepatitis & $2(1.5)$ \\
\hline Liver cirrhosis & $1(0.7)$ \\
\hline
\end{tabular}

Values are presented as mean \pm SD, median (range), or number (\%). PT (INR), prothrombin time (international normalized ratio); CEA, carcinoembryonic antigen; $C A$, carbohydrate antigen; $B M I$, body mass index; SD, standard deviation.

multiple logistic regression analyses, P-values less than 0.05 were considered to indicate a statistically significant difference. $R$ version 3.5.0 (The R Foundation for Statistical Computing, Vienna, Austria) 
was used for statistical analyses.

\section{Results}

\section{Baseline Characteristics of Patients and the Index Tumors}

A total of 136 patients (87 male and 49 female; mean age \pm standard deviation, $60.3 \pm 11.6$ years) constituted the study population (Table 1). The primary cancer was colon cancer in 89 patients and rectal cancer in 47 patients. Most patients $(97.8 \%, 133 / 136)$ did not have chronic hepatitis or liver cirrhosis. The median tumor size was $1.3 \mathrm{~cm}$ (range, 0.3 to $2.8 \mathrm{~cm}$ ). The median distance from the diaphragm to the tumor was $1.6 \mathrm{~cm}$ (range, 0 to $7.8 \mathrm{~cm}$ ). Slightly more than half $(51.5 \% ; 70 / 136)$ of the patients underwent chemotherapy before planning US, and $11.8 \%(16 / 136)$ of the patients had a history of hepatic resection prior to planning US.

\section{Feasibility of Percutaneous RFA}

Percutaneous RFA was considered infeasible in $24.3 \%$ (33/136) of the patients. The causes of the infeasibility of RFA were as follows: a high risk of the heat-sink effect due to the abutment of the large vessel $(n=12)$, inconspicuous tumors on planning US ( $n=11)$, a high risk of collateral thermal damage to the adjacent organ $(n=8$; heart

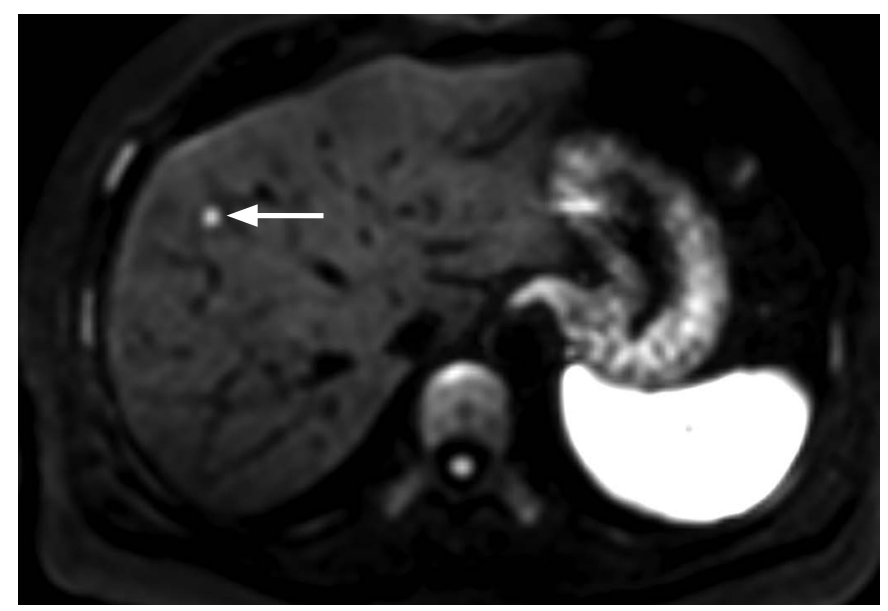

A

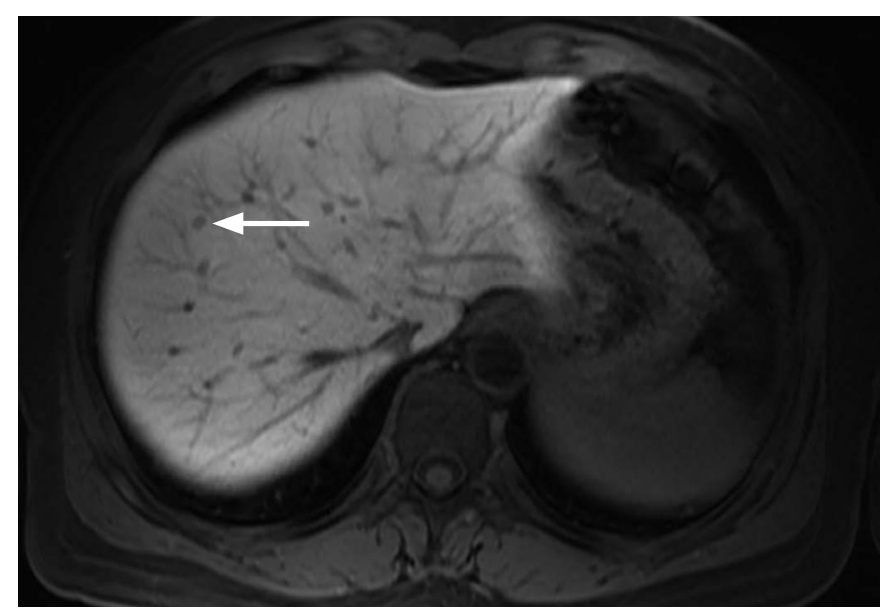

B

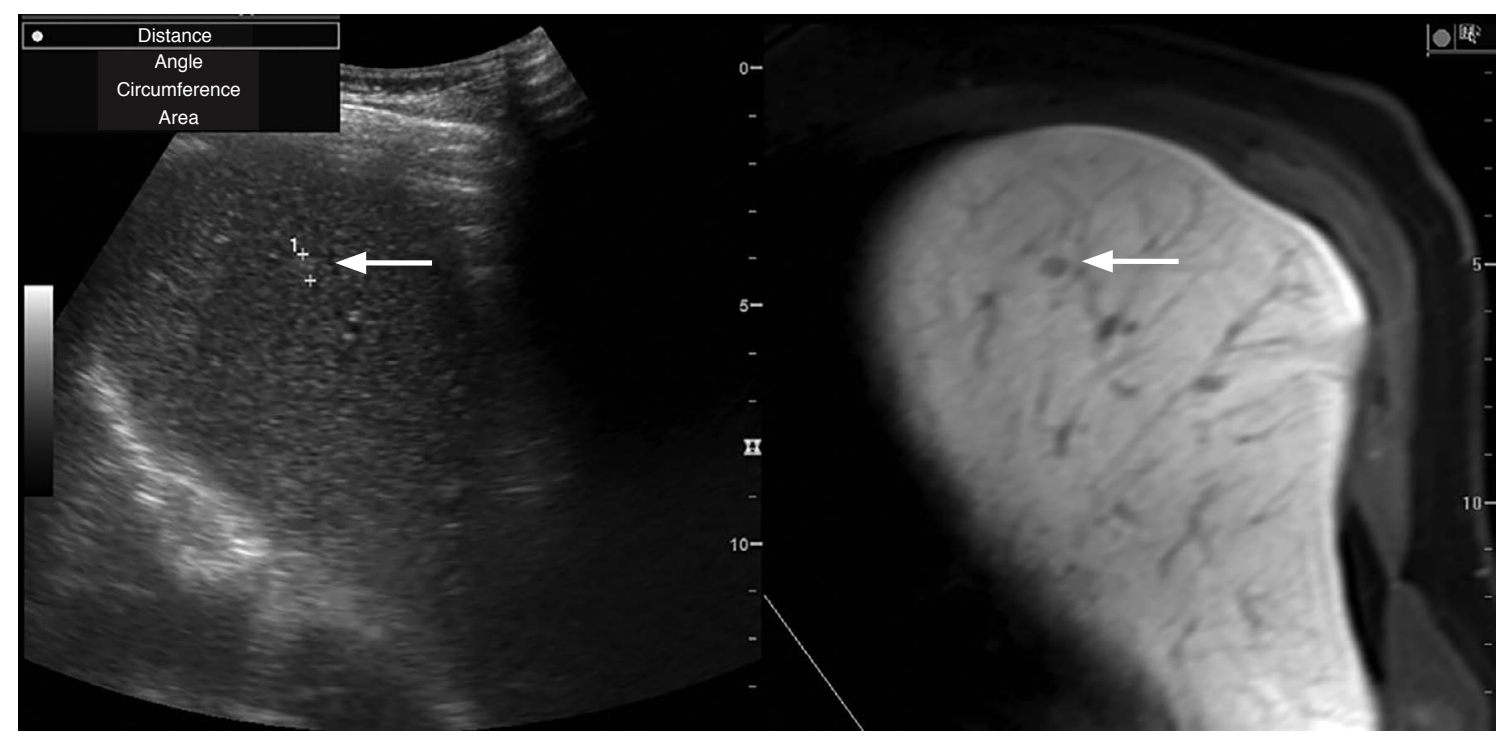

C

Fig. 2. A 48-year-old woman with a single hepatic metastasis from colon cancer.

A. Diffusion-weighted magnetic resonance image shows a $0.5-\mathrm{cm}$ metastasis (arrow) in segment VIII of the liver. B. Hepatobiliary phase magnetic resonance image shows the tiny metastasis (arrow). C. On planning ultrasonography performed in the semi-erect position, the lesion (arrows) is identified on B-mode ultrasonography (left) at the corresponding site of the fused hepatobiliary phase magnetic resonance image (right). 


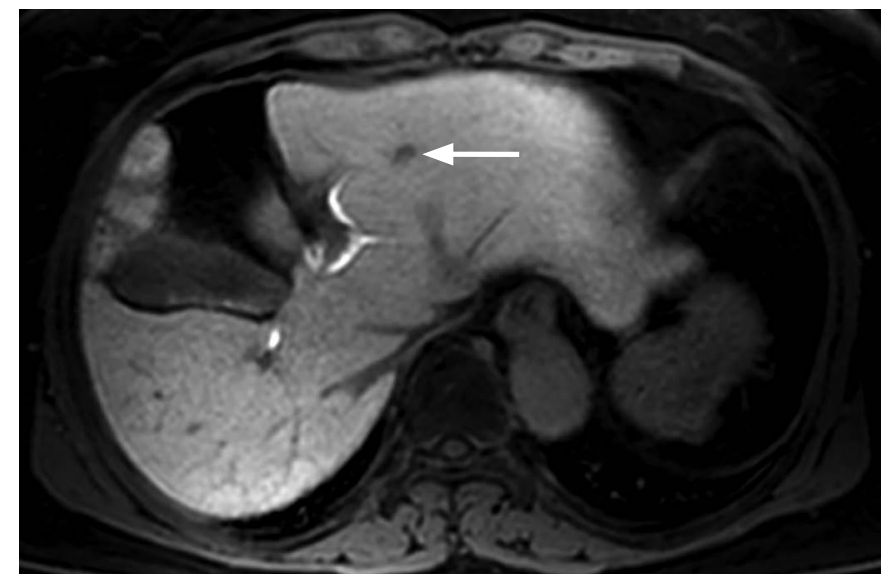

A

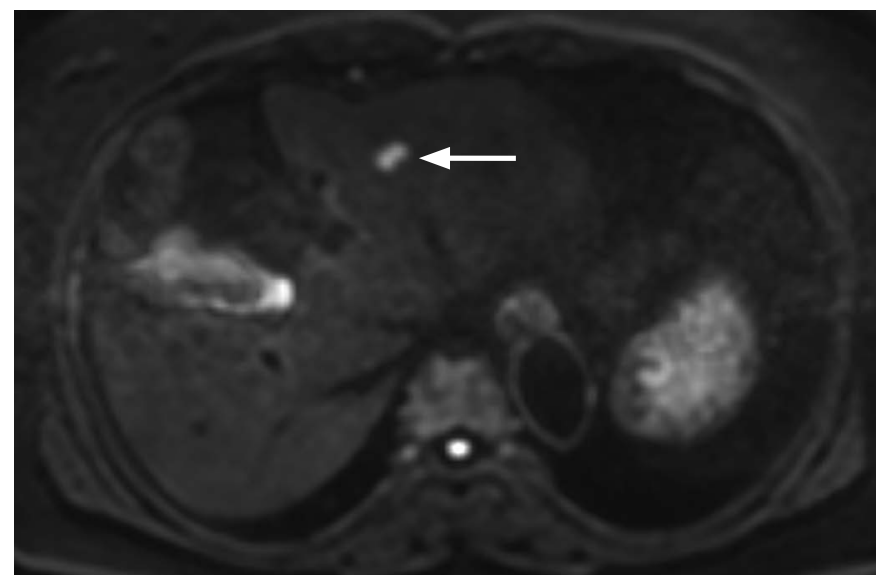

B

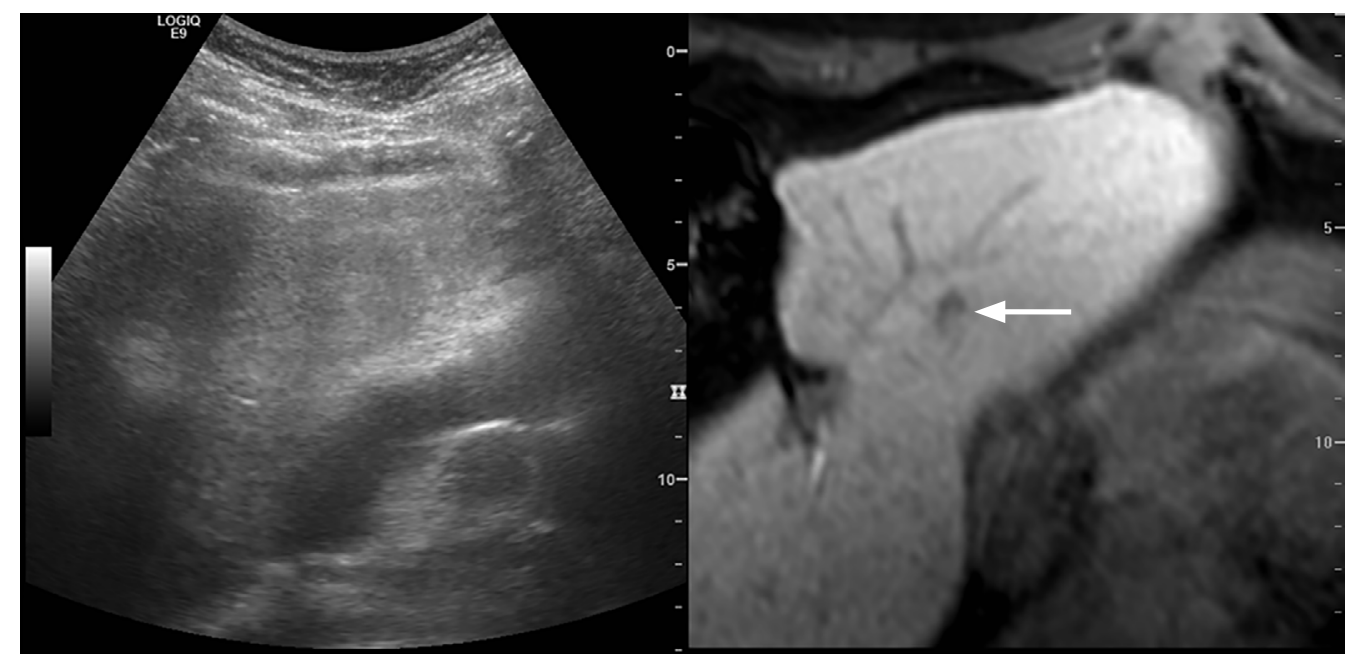

C

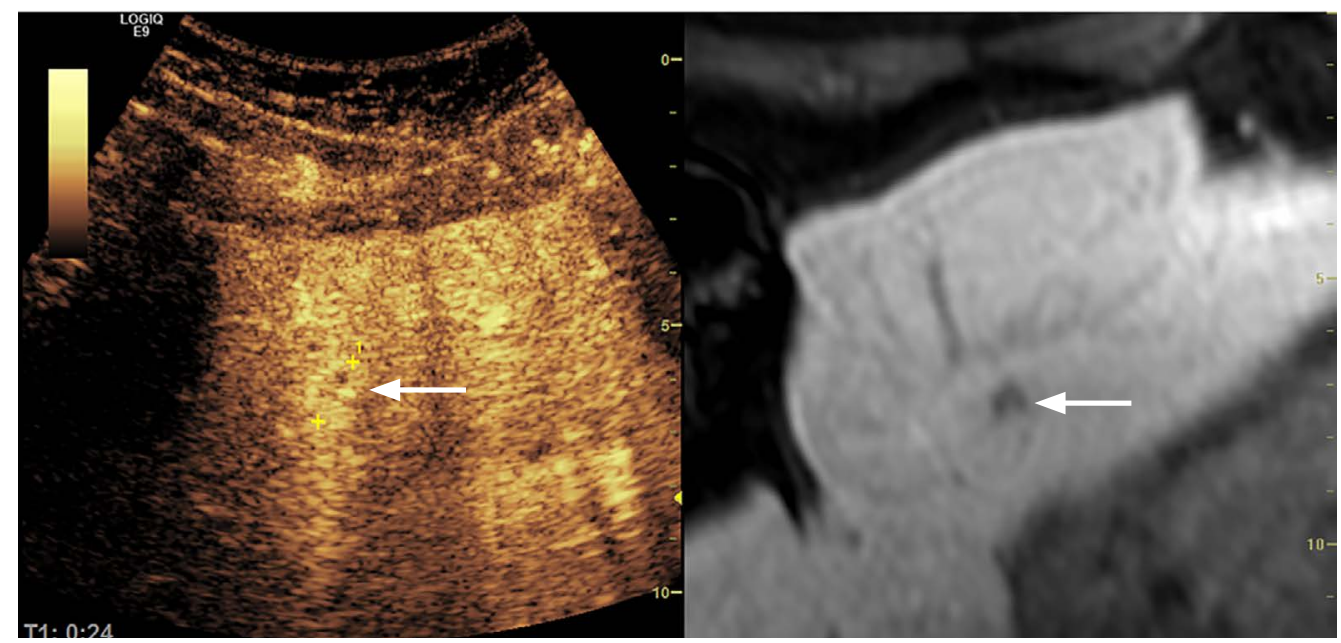

D

Fig. 3. A 68-year-old woman with a single metastatic lesion from colon cancer.

A. Hepatobiliary phase magnetic resonance image shows a $0.8-\mathrm{cm}$ metastasis (arrow) in segment III of the liver. B. The lesion is seen as a nodule (arrow) with high signal intensity on a diffusion-weighted magnetic resonance image. C. On planning ultrasonography, the metastasis (arrow) could not be identified on real-time US (left). D. Arterial-phase contrast-enhanced ultrasonography demonstrates a rim-enhancing metastasis (arrows) in a location similar to that on the fused magnetic resonance image. 
$[n=3]$, central bile duct $[n=2]$, the bare area of the diaphragm $[n=2]$, or gallbladder $[n=1])$, and the absence of a safe electrode path $(n=2)$.

\section{Visibility of the Index Tumor}

Of the 136 tumors in 136 patients, 13 lesions were not identified on B-mode US (Fig. 2). Two of those lesions could be visualized after CEUS (Fig. 3). CEUS was not performed in the remaining 11 patients
Table 2. The visibility of the tumor on planning ultrasonography according to tumor size

\begin{tabular}{cccc}
\hline $\begin{array}{c}\text { Tumor size } \\
(\mathrm{cm})\end{array}$ & $\begin{array}{c}\text { Visible } \\
(\mathrm{n}=125)^{\mathrm{a})}\end{array}$ & $\begin{array}{c}\text { Invisible } \\
(\mathrm{n}=11)^{\mathrm{a})}\end{array}$ & $\begin{array}{c}\text { Visibility rate, } \\
\mathrm{n}(\%)\end{array}$ \\
\hline$\leq 1$ & 36 & 9 & $36 / 45(80.0)$ \\
$1.1-2.0$ & 78 & 2 & $78 / 80(97.5)$ \\
$2.1-3.0$ & 11 & 0 & $11 / 11(100)$ \\
\hline
\end{tabular}

${ }^{a}$ The Fisher exact test revealed a statistically significant difference $(P=0.002)$.

Table 3. Comparison of the characteristics between visible and invisible lesions on planning ultrasonography

\begin{tabular}{|c|c|c|c|c|c|c|}
\hline \multirow{2}{*}{ Characteristic } & \multirow{2}{*}{ Visible $(n=125)$} & \multirow{2}{*}{ Invisible $(n=11)$} & \multirow{2}{*}{$\begin{array}{c}\text { Univariate } \\
\text { analysis (P-value) }\end{array}$} & \multicolumn{3}{|c|}{ Multiple logistic regression analysis } \\
\hline & & & & P-value & Odds ratio & $95 \% \mathrm{Cl}$ \\
\hline Sex & & & 0.057 & 0.442 & 0.515 & $0.095-2.794$ \\
\hline Female & 42 & 7 & & & & \\
\hline Male & 83 & 4 & & & & \\
\hline $\mathrm{BMI}\left(\mathrm{kg} / \mathrm{m}^{2}\right)$ & & & 0.097 & 0.075 & 0.143 & $0.017-1.219$ \\
\hline$<25$ & 77 & 10 & & & & \\
\hline$\geq 25$ & 48 & 1 & & & & \\
\hline Distance from the diaphragm (cm) & $1.7(0-7.8)$ & $0.7(0-5.8)$ & 0.099 & 0.311 & 0.783 & $0.488-1.257$ \\
\hline Tumor size $(\mathrm{cm})$ & $1.3(0.3-2.8)$ & $0.8(0.5-1.8)$ & 0.003 & 0.018 & 0.104 & $0.016-0.676$ \\
\hline Creatinine (mg/dL) & $0.8(0.4-3.0)$ & $0.7(0.4-1.1)$ & 0.070 & 0.540 & 0.307 & $0.007-13.343$ \\
\hline Age (year) & $60.6 \pm 11.7$ & $56.4 \pm 10.3$ & 0.219 & - & - & - \\
\hline Albumin (g/dL) & $4.4(3.0-5.1)$ & $4.1(3.6-4.8)$ & 0.191 & - & - & - \\
\hline Total bilirubin (mg/dL) & $0.5(0.2-2.4)$ & $0.4(0.2-1.0)$ & 0.386 & - & - & - \\
\hline PT (INR) & $1.0(0.9-1.5)$ & $1.0(1.0-1.2)$ & 0.261 & - & - & - \\
\hline Platelet count $\left(\times 10^{9} / \mathrm{L}\right)$ & $238.5(84-462)$ & $280(117-396)$ & 0.494 & - & - & - \\
\hline CEA (ng/mL) & $3.3(0.5-594.9)$ & $2.9(0.6-30.0)$ & 0.468 & - & - & - \\
\hline CA19-9 (U/mL) & $14.0(1.2-583.1)$ & $13.1(3.0-118.2)$ & 0.923 & - & - & - \\
\hline Segment & & & 0.175 & & & \\
\hline । & 7 & 0 & & - & - & - \\
\hline$\|$ & 7 & 0 & & - & - & - \\
\hline III & 9 & 2 & & - & - & - \\
\hline IV & 18 & 3 & & - & - & - \\
\hline V & 8 & 1 & & - & - & - \\
\hline VI & 27 & 0 & & - & - & - \\
\hline$V \|$ & 14 & 3 & & - & - & - \\
\hline VIII & 35 & 2 & & - & - & - \\
\hline Chemotherapy & & & 0.919 & & & \\
\hline No & 60 & 6 & & - & - & - \\
\hline Yes & 65 & 5 & & - & - & - \\
\hline Previous hepatic resection & & & 0.619 & & & \\
\hline No & 111 & 9 & & - & - & - \\
\hline Yes & 14 & 2 & & - & - & - \\
\hline Liver disease & & & $>0.99$ & & & \\
\hline No & 122 & 11 & & - & - & - \\
\hline Chronic hepatitis & 2 & 0 & & - & - & - \\
\hline Liver cirrhosis & 1 & 0 & & - & - & - \\
\hline
\end{tabular}

Values are presented as number, median (range) or mean \pm SD.

$\mathrm{Cl}$, confidence interval; BMI, body mass index; PT (INR), prothrombin time (international normalized ratio); CEA, carcinoembryonic antigen; CA, carbohydrate antigen; SD, standard deviation. 
mainly because of a deeply positioned tumor or an insufficient sonographic window. Consequently, 11 of the 136 lesions (8.1\%) were considered invisible on planning US. When tumor size was categorized into three groups $(\leq 1 \mathrm{~cm}, 1.1-2.0 \mathrm{~cm}$, and 2.1-3.0 $\mathrm{cm})$, the visibility of the tumor was different according to tumor size on planning US ( $\mathrm{P}=0.002$ ) (Table 2).

Table 3 compares the characteristics between the visible and invisible tumors on planning US. The distance from the diaphragm to the tumor was closer in the invisible than in the visible tumors (median, $0.7 \mathrm{~cm}$ vs. $1.7 \mathrm{~cm}$ ), but this was not statistically significant in the univariate and multivariate analyses $(P=0.099$ and $P=0.311$, respectively). The tumor size was significantly different between the two groups (median, $1.3 \mathrm{~cm}$ vs. $0.8 \mathrm{~cm}$; mean, $1.4 \mathrm{~cm}$ vs. 0.9 $\mathrm{cm})$ in both the univariate and multivariate analyses $(P=0.003$ and $\mathrm{P}=0.018$, respectively). The tumor size was the sole significant factor affecting the invisibility of hepatic metastasis on planning US.

\section{Discussion}

This study evaluated the results of planning US for metastatic colorectal cancer, and found that percutaneous RFA was infeasible in $24.3 \%$ (33/136) of cases. Percutaneous RFA was infeasible due to the following reasons: a high risk of the heat-sink effect due to the abutment of a large vessel, inconspicuous tumors, a high risk of collateral thermal damage to an adjacent organ, and the absence of a safe electrode path. Small tumor size was also found to be the only independent factor affecting tumor invisibility on planning US.

Tumor location (either the abutment of a large vessel or a highrisk location for collateral thermal damage) was the leading cause of the infeasibility of percutaneous RFA. This result is different from that of a previous study, in which an inconspicuous tumor on US was the most common cause of infeasibility in patients with HCC [7]. It is postulated that tumors in unfavorable locations might have been managed with surgical resection more frequently than with RFA in metastatic colorectal cancer because these patients mainly had normal livers with sufficient hepatic reserve function. On the contrary, patients with HCC might have undergone RFA if hepatic reserve function was insufficient, even though the tumor location was not favorable. These differences in patient population between metastatic colorectal cancer and HCC may have contributed to different results in terms of the infeasibility of percutaneous RFA.

In the present study, an inconspicuous tumor on planning US was the second most common cause of the infeasibility of RFA. However, the mean size of inconspicuous tumors in the present study was much smaller than that in the previous study in which planning US was performed in patients with HCCs $(0.9 \mathrm{~cm}$ vs. $1.4 \mathrm{~cm})$ [7]. The mean size of inconspicuous HCCs in another study was $1.3 \mathrm{~cm} \mathrm{[8],}$ which is larger than that in the present study. Several factors can explain this difference. First, most patients in this study had normal livers $(97.8 \%, 133 / 136)$, whereas most patients in the HCC cohort had chronic hepatitis or liver cirrhosis $[7,8,13]$. Considering that small HCCs are sometimes challenging to localize on US due to the coarse liver echotexture, surrounding cirrhotic nodules mimicking HCC, and poor sonographic window [17], the difference in tumor size between inconspicuous HCCs and inconspicuous metastatic colorectal cancers is not surprising. Second, the present study used advanced US technologies, including fusion imaging and CEUS, whereas conventional B-mode US was used in the aforementioned studies $[7,8,13]$. In this study, the mean size of inconspicuous metastases was only $0.9 \mathrm{~cm}$ because fusion imaging and CEUS are useful for localizing small tumors that are inconspicuous on B-mode US [15,18-23].

Unlike previous studies $[8,13]$, the distance from the diaphragm to the tumor was not a significant factor affecting tumor invisibility. Hepatic dome lesions might have been localized on planning US more frequently because the semi-erect position was used to improve the sonographic window for liver dome lesions whenever needed [14]. In addition, fusion imaging and CEUS were used to localize the tumors. Moreover, because most patients (97.8\%) had a normal liver, the sonographic window was much better in the present study cohort than in patients with chronic liver disease or liver cirrhosis.

This study has several limitations. First, this was a retrospective single-center study, and selection bias was unavoidable. Second, the assessment of tumor visibility and RFA feasibility was based on the decision of the attending radiologists, which may be subjective. This may be inevitable because US examinations have an intrinsic limitation in their subjective nature. Third, the results should be interpreted with caution because of the use of several advanced technologies, including fusion imaging and CEUS. In addition, the semi-erect position was used for planning US whenever needed to improve the sonographic window for hepatic dome lesions. Therefore, it was not possible for this study to determine the extent to which planning US can localize metastatic colorectal cancer when performed in the conventional supine position. The results in the supine position might be inferior to those in the present study. Meanwhile, CEUS was not performed on all subjects with inconspicuous tumors on fusion imaging, mainly due to poor sonographic window or deeply located tumor. Nonetheless, CEUS may be considered as a problem-solving tool for ablating small tumors when fusion imaging alone is not satisfactory for localizing small tumors [21,22].

In conclusion, when fusion imaging, CEUS, and a tilting table capable of the semi-erect position were used for planning US for metastatic colorectal cancer $<3 \mathrm{~cm}$, percutaneous RFA was 
infeasible in about one-fourth of patients. Infeasibility was mainly due to unfavorable tumor location and the invisibility of the tumor on planning US. Small tumor size was the sole significant factor affecting the invisibility of hepatic metastasis in planning US.

ORCID: Jeong Woo Bae: https://orcid.org/0000-0003-3851-961X; Min Woo Lee: https://orcid.org/0000-0001-9048-9011; Tae Wook Kang: https://orcid.org/00000002-0725-8317; Kyoung Doo Song: https://orcid.org/0000-0002-2767-3622; Dong Ik Cha: https://orcid.org/0000-0003-3271-6532; Ji Hye Min: https://orcid.org/00000002-8496-6771; Hyunchul Rhim: https://orcid.org/0000-0002-9737-0248

\section{Author Contributions}

Conceptualization: Bae JW, Lee MW. Data acquisition: Lee MW, Song KD, Kang TW, Cha DI, Min JH, Rhim H. Data analysis or interpretation: Bae JW, Lee MW. Drafting of the manuscript: Bae JW, Lee MW. Critical revision of the manuscript: Bae JW, Lee MW, Song KD, Kang TW, Cha DI, Min JH, Rhim H. Approval of the final version of the manuscript: all authors.

\section{Conflict of Interest}

No potential conflict of interest relevant to this article was reported.

\section{Acknowledgments}

We would like to thank Editage (www.editage.co.kr) for English language editing.

\section{References}

1. Martin J, Petrillo A, Smyth EC, Shaida N, Khwaja S, Cheow HK, et al. Colorectal liver metastases: current management and future perspectives. World J Clin Oncol 2020;11:761-808.

2. Yang G, Wang G, Sun J, Xiong Y, Li W, Tang T, et al. The prognosis of radiofrequency ablation versus hepatic resection for patients with colorectal liver metastases: a systematic review and meta-analysis based on 22 studies. Int I Surg 2021;87:105896.

3. Nordlinger B, Guiguet M, Vaillant JC, Balladur P, Boudjema K, Bachellier $\mathrm{P}$, et al. Surgical resection of colorectal carcinoma metastases to the liver: a prognostic scoring system to improve case selection, based on 1568 patients. Association Francaise de Chirurgie. Cancer 1996;77:1254-1262.

4. Gillams A, Goldberg N, Ahmed M, Bale R, Breen D, Callstrom M, et al. Thermal ablation of colorectal liver metastases: a position paper by an international panel of ablation experts, The Interventional Oncology Sans Frontieres meeting 2013. Eur Radiol 2015;25:34383454.

5. Shady W, Petre EN, Gonen M, Erinjeri JP, Brown KT, Covey AM, et al. Percutaneous radiofrequency ablation of colorectal cancer liver metastases: factors affecting outcomes: a 10-year experience at a single center. Radiology 2016;278:601-611.

6. Rhim H, Lee MH, Kim YS, Choi D, Lee WJ, Lim HK. Planning sonography to assess the feasibility of percutaneous radiofrequency ablation of hepatocellular carcinomas. AJR Am J Roentgenol 2008;190:1324-1330.

7. Kim JE, Kim YS, Rhim H, Lim HK, Lee MW, Choi D, et al. Outcomes of patients with hepatocellular carcinoma referred for percutaneous radiofrequency ablation at a tertiary center: analysis focused on the feasibility with the use of ultrasonography guidance. Eur J Radiol 2011;79:e80-e84.

8. Kim PN, Choi D, Rhim H, Rha SE, Hong HP, Lee J, et al. Planning ultrasound for percutaneous radiofrequency ablation to treat small $(\leq 3 \mathrm{~cm})$ hepatocellular carcinomas detected on computed tomography or magnetic resonance imaging: a multicenter prospective study to assess factors affecting ultrasound visibility. J Vasc Interv Radiol 2012;23:627-634.

9. Hakime A, Yevich S, Tselikas L, Deschamps F, Petrover D, De Baere T. Percutaneous thermal ablation with ultrasound guidance: fusion imaging guidance to improve conspicuity of liver metastasis. Cardiovasc Intervent Radiol 2017;40:721-727.

10. Lee MW, Rhim H, Cha DI, Kim YJ, Lim HK. Planning US for percutaneous radiofrequency ablation of small hepatocellular carcinomas $(1-3 \mathrm{~cm})$ : value of fusion imaging with conventional US and CT/MR images. J Vasc Interv Radiol 2013;24:958-965.

11. Lee MW. Fusion imaging of real-time ultrasonography with $\mathrm{CT}$ or MRI for hepatic intervention. Ultrasonography 2014;33:227-239.

12. Minami T, Minami Y, Chishina H, Arizumi T, Takita M, Kitai S, et al. Combination guidance of contrast-enhanced US and fusion imaging in radiofrequency ablation for hepatocellular carcinoma with poor conspicuity on contrast-enhanced US/fusion imaging. Oncology 2014;87 Suppl 1:55-62.

13. Lee MW, Kim YJ, Park HS, Yu NC, Jung SI, Ko SY, et al. Targeted sonography for small hepatocellular carcinoma discovered by $\mathrm{CT}$ or MRI: factors affecting sonographic detection. AJR Am J Roentgenol 2010;194:W396-W400.

14. Ko SE, Lee MW, Lim HK, Min JH, Cha DI, Kang TW, et al. The semierect position for better visualization of subphrenic hepatocellular carcinoma during ultrasonography examinations. Ultrasonography 2021;40:274-280.

15. Song KD, Lee MW, Rhim H, Kang TW, Cha DI, Sinn DH, et al. Percutaneous US/MRI fusion-guided radiofrequency ablation for recurrent subcentimeter hepatocellular carcinoma: technical feasibility and therapeutic outcomes. Radiology 2018;288:878886.

16. Lu DS, Raman SS, Limanond P, Aziz D, Economou J, Busuttil R, et al. Influence of large peritumoral vessels on outcome of radiofrequency ablation of liver tumors. J Vasc Interv Radiol 2003;14:1267-1274.

17. Lee MW, Lim HK, Kim YJ, Choi D, Kim YS, Lee WJ, et al. Percutaneous sonographically guided radio frequency ablation 
of hepatocellular carcinoma: causes of mistargeting and factors affecting the feasibility of a second ablation session. J Ultrasound Med 2011;30:607-615.

18. Mauri G, Cova L, De Beni S, lerace T, Tondolo T, Cerri A, et al. Realtime US-CT/MRI image fusion for guidance of thermal ablation of liver tumors undetectable with US: results in 295 cases. Cardiovasc Intervent Radiol 2015;38:143-151.

19. Minami Y, Kudo M. Ultrasound fusion imaging of hepatocellular carcinoma: a review of current evidence. Dig Dis 2014;32:690-695.

20. Choi MH, Choi JI, Lee YJ. Manual versus automated image fusion of real-time ultrasonography and MR/CT images for radiofrequency ablation of hepatic tumors: results of a randomized prospective trial (NCT02705118). Ultrasonography 2021;40:237-247.

21. Lee MW, Lim HK, Rhim H, Cha DI, Kang TW, Song KD, et al. Percutaneous radiofrequency ablation of small (1-2 $\mathrm{cm})$ hepatocellular carcinomas inconspicuous on B-mode ultrasonographic imaging: usefulness of combined fusion imaging with MRI and contrast-enhanced ultrasonography. Can J Gastroenterol Hepatol 2018;2018:7926923.

22. Min JH, Lim HK, Lim S, Kang TW, Song KD, Choi SY, et al. Radiofrequency ablation of very-early-stage hepatocellular carcinoma inconspicuous on fusion imaging with B-mode US: value of fusion imaging with contrast-enhanced US. Clin Mol Hepatol 2014;20:61-70.

23. Bo $X W$, $X u H X$, Wang $D$, Guo $L H$, Sun $L P$, Li XL, et al. Fusion imaging of contrast-enhanced ultrasound and contrast-enhanced $C T$ or MRI before radiofrequency ablation for liver cancers. $\mathrm{Br} J$ Radiol 2016;89:20160379. 